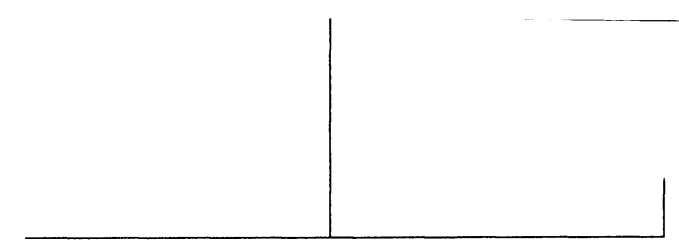

\title{
A paranóia, segundo Juliano Moreira e Afranio Peixoto
}

\author{
Ana Maria Galdini Raimundo Oda \\ Paulo Dalgalarrondo
}

Sobre o lugar da paranóia

O artigo "A paranóia e as síndromes paranóides", de Juliano Moreira e Afranio Peixoto, ocupa um lugar fundador na psiquiatria brasileira e na investigação psicopatológica realizada no país. Ele abre a primeira publicação nacional especializada nesta área, os Arquivos Brasileiros de Psiquiatria, Neurologia e Ciências Afins, nascida em abril de 1905 e fundada por esses dois autores.

Sua primeira publicação foi no Brasil Médico, em 1904 (Carvalhal \& Delgado, 1998), a seguir na edição inaugural dos Arquivos em 1905, tendo uma reedição em 1955, em número comemorativo aos 50 anos da revista. Além disso, o trabalho foi apresentado, em 1904, no III Congresso Latinoamericano de Medicina, em Buenos Aires e, em 1906, no XV Congresso Internacional de Medicina, em Lisboa (Peixoto, 1938).

Pode-se supor que a escolha de tal tema tivesse uma especial significação para os autores, ou seja, que discorrer sobre o que deveria ou não ser chama- 


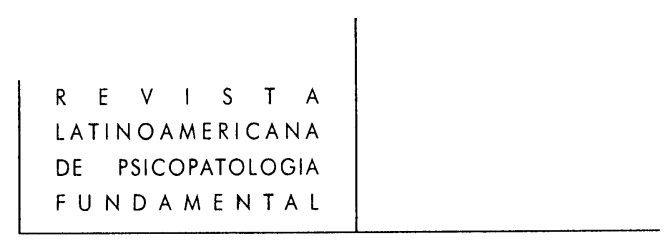

do de paranóia' fosse uma forma privilegiada de explicitar e delimitar as suas posições teóricas, fundamentalmente o alinhamento à escola psicopatológica alemã, de Kraepelin, em contraposição à tradicional francofilia do alienismo brasileiro, até então.

Esta suposição é reforçada pelo exame dos artigos constantes no volume correspondente ao primeiro ano da revista, em que se evidencia o referido alinhamento teórico, em especial nos textos: "Classificação das moléstias mentais do Prof. Emil Kraepelin" (Moreira \& Peixoto, 1905b); "A loucura maníaco-depressiva" (Peixoto, 1905) e "Sobre a psicose maníaco-depressiva" (Franco da Rocha, 1905). Além desses artigos originais, há ainda a tradução do capítulo sobre a paranóia (Verrücktheit) da edição de 1904 da obra Die Psychiatrie, de Kraepelin (Austregésilo, 1905a) e as resenhas sobre os trabalhos "A concepção da paranóia", de Adelino Pinto e "A paranóia segundo Kraepelin", de Ulysses Vianna Filho (Austregésilo, 1905b e 1905c). Mesmo na escolha dos pacientes que tiveram publicadas, no fim de cada número da revista, suas versas, a preferência pelo tema se mostra: "escritos de dois dementes paranóides", um "poemeto por um paranóico" e "fragmentos poéticos de um degenerado epiléptico".

Em "A paranóia e as síndromes paranóides", depois de tecerem considerações teóricas sobre a origem da paranóia e sobre a delimitação de seu conceito, os autores apresentam detalhadas observações clínicas, em suas palavras, as "espécies mórbidas que tínhamos à disposição" (doze homens e uma mulher) - o primeiro caso tem o diagnóstico de paranóia e do segundo ao décimo-terceiro, as síndromes paranóides se fazem presentes em casos diagnosticados primariamente como neurastenia constitucional, epilepsia, degeneração inferior, psicose tóxica (alcoolismo), psicose autotóxica (obesidade, dismenorréia), psicose infecciosa (malária), loucura maníaco-depressiva de predominância maníaca, loucura maníaco-depressiva de predominância melancólica, melancolia de involução, demência precoce, involução senil e demência paralítica.

A apresentação dos casos segue, em geral, o seguinte roteiro de anamnese: identificação (idade, cor, nacionalidade, estado civil, profissão), antecedentes mórbidos familiares e pessoais, observações sobre a infância e juventude do paciente e sobre

1. Nas palavras de Emil Kraepelin, o nome de paranóia deveria ser reservado a “... um grupo de casos nos quais as concepções delirantes, se bem que não constituam exclusivamente o quadro clínico, são todavia o indício mórbido que mais se sobressai. Neste grupo costuma-se desenvolver um inabalável sistema delirante lento e duradouro, com completa conservação do discernimento, clareza e ordem na associação do pensamento, da vontade e da ação." (Kraepelin, E. Paranóia. Tradução de A. Austregésilo. Arquivos Brasileiros de Psiquiatria, Neurologia e Ciências Afins. I (1):103, 1905a). 


\section{CLÁSSICOS DA}

PSICOPATOLOGIA

a constituição familiar, presença ou ausência de sinais físicos de degeneração, história da doença e descrição do quadro sintomático atual, com notas sobre a evolução clínica e sobre o tratamento realizado.

\section{Sobre Juliano Moreira}

Cabe a Juliano Moreira (1873-1933) grande parte da responsabilidade pela mudança na filiação do nosso alienismo, bem como pela consolidação da psiquiatria como disciplina científica autônoma na medicina. Alguns aspectos de sua biografia auxiliam na compreensão do lugar ocupado por Juliano neste processo. Nascido na Bahia, era mulato, filho de família modesta, tendo se graduado aos 18 anos (1891) na Faculdade de Medicina daquele Estado, com a tese Sífilis maligna precoce. Cinco anos depois foi admitido, após brilhante participação em concurso público, como professor substituto da seção de doenças nervosas e mentais da mesma escola. $\mathrm{Na}$ Europa, freqüentou cursos de psiquiatria com os mestres locais e visitou asilos na Alemanha, Inglaterra, França, Itália e Escócia, de 1895 a 1902.

De 1903 a 1930 dirigiu o Hospício Nacional de Alienados, no Rio de Janeiro. Lá recebia internos para o ensino de psiquiatria e influenciou a formação de muitos profissionais que viriam a ter participação expressiva em diversas áreas da medicina brasileira, na neurologia, psiquiatria, medicina legal, clínica médica, patologia clínica, anatomia patológica e pediatria. Dentre eles, destacam-se Afranio Peixoto, Antonio Austregésilo, Franco da Rocha, Ulysses Vianna, Heitor Carrilho, Henrique Roxo, Fernandes Figueira e Miguel Pereira (Oda \& Dalgalarrondo, 2000).

Além da preocupação com a modernização teórica da psiquiatria, ressaltava em seus escritos a necessidade de transformar a prática asilar; quando assumiu a direção do Hospício Nacional de Alienados passou à ação, instalando laboratórios de anatomia patológica e de bioquímica, remodelando o corpo clínico, incluindo novos neuropsiquiatras e especialistas em clínica médica, pediatria, oftalmologia, ginecologia e odontologia; cuidou também da formação dos enfermeiros. Preocupado em criar um ambiente terapêutico, aboliu o uso de camisas de força e de grades de ferro das janelas. Articulou a aprovação e defendeu a primeira lei federal de assistência aos alienados, promulgada em 1903 (Moreira, 1905); sua atuação institucional incluiu ainda a organização da Assistência aos Alienados, depois Serviço Nacional de Assistência aos Psicopatas.

Publicou, no início da carreira, estudos nas áreas de sifiligrafia, dermatologia e infectologia. Depois, cada vez mais se dedicou às doenças mentais, discutindo a nosografia psiquiátrica, estudando as histórias da medicina e da assistência psiquiátrica no Brasil, escrevendo sobre modelos assistenciais e sobre a legislação referente aos alienados (Carvalhal \& Delgado, 1998). 


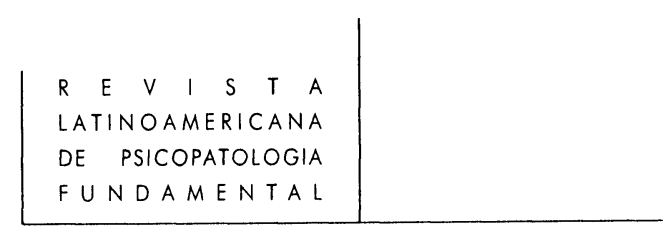

As cartas trocadas com Emil Kraepelin, além de diversos artigos publicados, demonstram seu interesse pela chamada psiquiatria comparada, ou seja, pelas diferentes manifestações das doenças mentais em culturas diversas (Dalgalarrondo, 1996) .

\section{Sobre Afranio Peixoto}

Afranio Peixoto (1876-1947), como seu mestre e depois parceiro Juliano Moreira, nasceu na Bahia e consolidou sua vida profissional na antiga capital federal.

Sua tese de formatura, apresentada à Faculdade de Medicina da Bahia em 1897, foi Epilepsia e crime, mostrando seu interesse pela criminologia, tema em voga na época. Estudou medicina legal em Viena, Berlim e Paris, preparando-se para concorrer ao cargo de professor da Faculdade de Medicina do Rio de Janeiro.

Tendo intensa participação política, Peixoto foi responsável pela articulação que levou J. Moreira ao cargo de diretor do Hospício Nacional, em 1903 - sendo também médico do Hospício, substituiu o diretor em diversas ocasiões, e com ele foi co-fundador da Sociedade Brasileira de Psiquiatria, Neurologia e Medicina Legal, em 1907.

Teve importantes cargos de chefia na administração pública, nos setores de saúde e de educação, tendo sido diretor do Instituto Médico Legal. Deputado federal, obteve aprovação, em 1927, de lei referente à reorganização da assistência aos doentes mentais (que de alienados passaram a ser denominados psicopatas); romancista e crítico literário, presidiu a Academia Brasileira de Letras (Corrêa, 1982).

Como se vê, exerceu uma ampla gama de influências, tanto técnicas quanto políticas, em variados campos. Recorde-se que, nesse momento histórico, ocorria a consolidação do processo de medicalização da sociedade brasileira, e os autodenominados homens de ciência tomaram para si a prerrogativa de ditar os destinos da nação, dentro e fora do Estado (Corrêa, 1982). Neste sentido, as trajetórias pessoais de Afranio Peixoto e de Juliano Moreira refletiram o caminho que estava sendo trilhado pela medicina brasileira, no início do século XX.

\section{Observações sobre A paranóia e as síndromes paranóides}

O texto se estrutura como clássico artigo médico: após breve introdução, descreve a etiopatogenia, a sintomatologia e o diagnóstico diferencial da doença e, por fim, apresenta observações clínicas ilustrativas. Seu objetivo é delimitar claramente a doença a ser chamada paranóia, diferenciando-a de outros estados em que ocorrem idéias ou delírios paranóides, considerados epifenômenos de várias doenças mentais. 
Primeiramente, há a afirmação de que a paranóia é relativamente rara, se devidamente diagnosticada, e as estatísticas de nossos autores são similares às referidas por Kraepelin.

A seguir, coloca-se a questão da etiologia da paranóia e Moreira e Peixoto fazem irônicos comentários sobre o que consideram abusos da teoria da degenerescência de Morel/Magnan². Embora não neguem sua existência, limitam muito a sua presumida ação.

Ainda com relação à teoria da degenerescência no Brasil, vale ressaltar a discordância de J. Moreira quanto à atribuição da degeneração do povo brasileiro à mestiçagem e a uma suposta contribuição negativa dos negros na miscigenação, conforme se posicionou em outro artigo (Moreira, 1908), onde explicita sua divergência do professor de medicina legal da Faculdade de Medicina da Bahia, Raimundo Nina Rodrigues (1862-1906), que sustentava justamente o contrário (Oda, 2000).

Mais tarde, Moreira diria que o trabalho médico não deveria ser afetado por "ridículos preconceitos de cores ou castas", pois na luta contra as degenerações nervosas os inimigos a combater eram o alcoolismo, a sífilis, as verminoses, as precárias condições sanitárias e educacionais (Moreira, 1922).

No artigo ora republicado, há outra explícita discordância dos autores com Nina Rodrigues (embora este não seja citado nominalmente) no que se refere ao conceito de atavismo, ao delírio como revivescência de fenômenos que teriam sido normais em épocas remotas. Seguindo os italianos Tanzi e Riva, Nina Rodrigues tinha na noção de atavismo psíquico uma das bases de suas teorias sobre os atos violentos ou criminosos e sua relação com a doença mental, especialmente entre os mestiços (Nina Rodrigues, 1939/1901). Para Moreira e Peixoto, a idéia de atavismo é absurda e descartável: "O atavismo é uma mera fantasia (...). Tenhamos, pois, a boa fé de procurar em nós, principalmente no meio em que vivemos, as causas de nossos males ...".

2. No início do século XX, o conceito de degeneração ou degenerescência era ainda extremamente popular, em especial entre os psiquiatras franceses e italianos. Esta teoria foi sistematizada por Bénédict Augustin Morel (1809-1873), no Tratado das degenerescências, de 1857, onde a degenerescência se definia como desvio de um tipo primitivo perfeito, transmissível hereditariamente. Depois de 1870, Valentin Magnan (1835-1916) redefiniu a degenerescência à lụz do evolucionismo, considerando-a um estado patológico, em que o desequilíbrio físico e mental do indivíduo degenerado interromperia o progresso natural da espécie; certos tipos específicos de loucura estariam associados à degenerescência - todo degenerado seria um desequilibrado mental, mas nem todo louco seria degenerado. A degenerescência poderia ser herdada ou adquirida e se manifestaria em sinais físicos, intelectuais e/ou comportamentais, chamados estigmas (Bercherie, P. Os fundamentos da clínica: história e estrutura do saber psiquiátrico. Rio de Janeiro: Zahar, 1989, p. 149-160). 


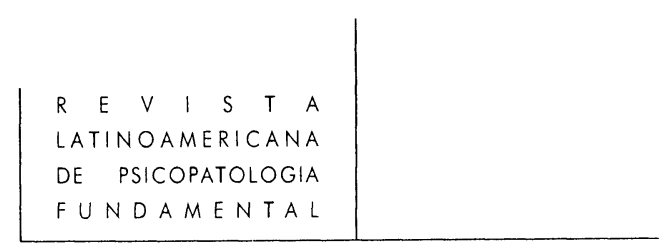

Os autores consideram que, sempre havendo um terreno preparado pela "real degenerescência", as variantes da paranóia se apresentariam em uma escala com gradações que iriam da anomalia à doença, da simples alteração de caráter (vaidade, presunção, jactância....) aos quadros francamente delirantes. Sem uma causa ocasional que desencadeasse o delírio, dizem eles, muitos paranóicos passariam toda vida despercebidos...

Sobre a ação da degeneração parece haver certa ambigüidade nas afirmações de Moreira e Peixoto: se, por um lado, afirmam ser ela "a leira preparada para o cultivo de todas as aberrações", todavia reconhecem que tal noção carecia de delimitação, "por não ter sido esclarecida sua intimidade mórbida" - não lhes parecendo muito útil, portanto.

Mais do que na degeneração, a ênfase na explicação da origem da paranóia é colocada em aspectos psicossociais: "... por deficiência de educação, de treinamento, de cultura..." a autofilia originária , normal, se tornaria egocentrismo patológico, resultando em conseqüente inadaptação ao meio, interpretação auto-referente persecutória como reação e, a partir daí, o início dos sinais explícitos de paranóia.

Fiéis à psicopatologia kraepeliniana, os autores descrevem a sintomatologia $\mathrm{e}$ o curso da enfermidade com detalhes - o paranóico começaria apresentando comportamento suspeitoso, denotando sua grande susceptibilidade, até chegar à total desconfiança "... tudo assume para eles um ar agressivo e nada é indiferente às suas preocupações. Fazem passar pela sua pessoa todas as coordenadas do mundo"4. Como reação de defesa às supostas hostilidades, tentam fugir, "... são andarilhos; quando não podem mudar de terra, mudam de bairro, mudam de casa, mudam de quarto, mudam de hábitos".

Haveria sempre uma idéia fixa que serviria de eixo às concepções paranóicas, sendo inamovível e irredutível a qualquer ataque lógico ou evidência da realidade. Contrariada esta idéia fixa, ocorreria a instalação do delírio de perseguição, ten-

3. A noção de autofilia originária evoca o conceito de narcisismo, central na compreensão psicanalítica das psicoses, mas é anterior a esta concepção de Freud. Segundo Laplanche e Pontalis, o termo aparece pela primeira vez em Freud em 1910, sendo sistematizado em 1914, na obra Para introdução do narcisismo (Zur Einführung des Narzissmus) (Laplanche, J. e Pontalis, J-B. Vocabulário da psicanálise. 10" ed. São Paulo: Martins Fontes, 1988, p. 365).

4. Kraepelin diz que a paranóia é uma "loucura de posição" (Verrïkung), quando a doença mental leva a uma completa modificação na maneira de encarar a vida. (Kraepelin, E. Paranóia. Op. (it.).

Muitos anos depois, Kurt Beringer irá denominar tal movimento, no contexto da psiquiatria fenomenológico-existencial, de "inversão do arco intencional". Não é o sujeito e sua consciência que se dirigem ao mundo, mas, para o paranóico, o mundo todo é que se dirige a ele. 
do como agravantes as alucinações e as falsas interpretações; a seguir, viriam as idéias de grandeza: os doentes "adaptam o que são ao que supõem dever ser". A percepção das impressões externas permaneceria preservada por muito tempo, as alucinações sobreviriam tardiamente, raras, predominando as auditivas.

Quanto à sua conduta, embora afirmem que a eterna luta do paranóico com o meio o transforme "no mais incômodo e mais perigoso dos insanos", adiante ressalvam que poucas vezes ele representaria ameaça concreta à sociedade: quase sempre nesses casos, dizem, "má-criação não é valentia". Mais do que perigosos, seriam cansativos: “... são doentes insuportáveis, a paciência se gasta em aturá-los em suas eternas queixas, recriminações, protestos, ameaças...".

Em resumo, para Moreira e Peixoto, o diagnóstico da paranóia se funda na suposição dos seguintes mecanismos: autofilia originária tornada egocentrismo pela educação; inadaptação do eu ao meio e conseqüente ideação persecutória; ações e reações resultantes desta persecutoriedade. São consideradas como características fundamentais do quadro: a sistematização das idéias delirantes, os delírios fixos, de longa duração, verossímeis, com falsificação retrospectiva da memória, a raridade das alucinações, a inteligência preservada e a ausência de terminação demencial. Todas estas marcantes e duradouras características da paranóia são contrastadas com certos conjuntos de sinais e sintomas fugazes e polimorfos, as síndromes paranóides, que acompanham outras doenças mentais (como as psicoses agudas decorrentes de intoxicações) e com o inevitável comprometimento intelectivo nas demências (nos quadros senis e na então chamada demência precoce, hoje esquizofrenia).

Tendo reconhecido a limitada contribuição da anatomia patológica para a construção de uma nosografia psiquiátrica consistente, Kraepelin baseou sua psicopatologia na descrição detalhada dos sinais e sintomas dos doentes mentais; ao agrupar os casos não só conforme suas características sintomáticas comuns, mas, principalmente, de acordo com sua evolução, ele tinha a esperança de vir a delimitar entidades nosológicas no sentido estrito do termo, ou seja, formas específicas de moléstias mentais, com uma história natural determinada.

Assim, as descrições clínicas presentes em todo o artigo (e especialmente no final) dizem muito dos referenciais teóricos dos nossos autores, sobre seus pressupostos a respeito da doença mental, tanto naquilo que ressaltam quanto no que deixam de lado, na formulação dos casos. A análise da linguagem usada pelos psiquiatras no processo de construção da sua nosografia e a decodificação das regras que controlam o discurso psiquiátrico são instrumentos que possibilitam uma abordagem interna da história da psicopatologia, sempre considerando que a observação clínica nunca foi (nem é, no presente) uma atividade inocente ou neutra, mas comprometida com os contextos históricos, psicológicos e filosóficos em que ocorreu (Berrios, 1996). 


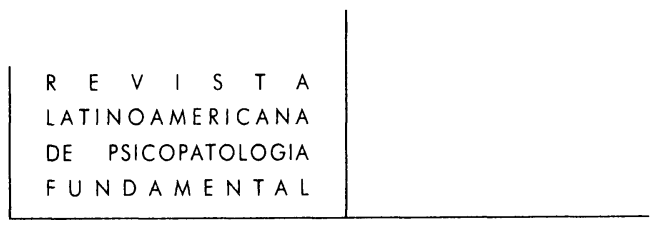

O estudo da história traz, cremos, uma salutar relativização dos nossos conceitos e práticas atuais; restaurar a genealogia do conhecimento permite reconhecer a determinação cultural de toda prática dita científica. É o que esperamos ter apontado neste breve comentário sobre o importante artigo de Juliano Moreira e Afranio Peixoto, cuja republicação certamente estimulará mais aprofundados estudos.

Agradecemos à historiadora Lázara Azevedo Carvalhal, do Instituto Franco Basaglia (RJ), pela gentil presteza com que nos enviou a edição de 1955 do artigo aqui republicado.

\section{Referências bibliográficas}

Austregésilo, A. Tradução do artigo sobre Paranóia, do Prof. Kraepelin. Arquivos Brasileiros de Psiquiatria, Neurologia e Ciências Afins. I (1): 98-106; (2): 183-196; (3): 301-309, 1905a.

Bibliografia: Dr. Ulisses Viana Filho - A paranóia (segundo Kraepelin). Tese. Bahia, 1904. Arquivos Brasileiros de Psiquiatria, Neurologia e Ciências Afins. I (1): 134-135, 1905b.

Bibliografia: Dr. Adelino Pinto - A concepção de paranóia. Tipografia do Hospício Nacional, 1905. Arquivos Brasileiros de Psiquiatria, Neurologia e Ciências Afins. I (3): 329-332, 1905c.

Berrios, G.E Introducion. In __ The History of Mental Symptoms: Descriptive Psychopatology since the Nineteenth Century. Cambridge: Cambridge University Press, 1996, p. 1-3.

Carvalhal, L.A. \& Delgado, P.G.G. Levantamento das fontes primárias e secundárias relativas a Juliano Moreira (1873-1933). Trabalho apresentado no Seminário sobre História da Psiquiatria - A loucura da (na) História (ENSP/FIOCRUZ), Rio de Janeiro, 1998.

CORRÊA, M. Conexões. In As ilusões da liberdade: a escola de Nina Rodrigues e a antropologia no Brasil. Tese de doutoramento. São Paulo, Universidade de São Paulo, 1982, p. 157-176.

Dalgalarrondo, P. Cartas de Juliano Moreira a Emil Kraepelin. In Civilização e loucura: uma introdução à história da etnopsiquiatria. São Paulo: Lemos, 1996, p. $117-124$.

Franco da Rocha, F. Sobre a psicose maníaco-depressiva. Arquivos Brasileiros de Psiquiatria, Neurologia e Ciências Afins. I (3): 279-288, 1905.

Moreira, J. Notícia sobre a evolução da assistência a alienados no Brasil. Arquivos Brasileiros de Psiquiatria, Neurologia e Ciências Afins. I (1): 52-98, 1905. 
. Querelantes e pseudo-querelantes. Arquivos Brasileiros de Psiquiatria, Neurologia e Medicina Legal. IV: 426-434, 1908.

. A luta contra as degenerações nervosas e mentais no Brasil (comunicação apresentada no Congresso Nacional dos Práticos). Brasil Médico, II: 225-226, 1922.

\& Pегхото, A. A paranóia e as síndromes paranóides. Arquivos Brasileiros de

Psiquiatria, Neurologia e Ciências Afins. I (1): 5-33, 1905a. (Reeditado em 1955, edição especial, p. 27-49).

\& ___ . Classificação de moléstias mentais do Prof. Emil Kraepelin. Arquivos Brasileiros de Psiquiatria, Neurologia e Ciências Afins. I (2): 204-216 e (3): 310-316, 1905b.

Nina Rodrigues, R. A loucura das multidões - nova contribuição ao estudo das loucuras epidêmicas no Brasil. In As coletividades anormais. Organização, prefácio e notas de Artur Ramos. Rio de Janeiro: Civilização Brasileira, 1939, p. 78-152. (Originalmente publicado em francês, em 1901).

OdA, A.M.G.R. Nina Rodrigues e a loucura epidêmica de Canudos. Revista Latinoamericana de Psicopatologia Fundamental. v. III, n. 2, p. 139-144, 2000.

. \& DalgalarRondo, P. Juliano Moreira: um psiquiatra negro frente ao racismo científico. Rev. Bras. Psiquiatr. 22 (4): 178-9, 2000.

Peixoto, A. A loucura maníaco-depressiva. Arquivos Brasileiros de Psiquiatria, Neurologia e Ciências Afins. I (1): 33-46, 1905.

. Paranéa. In Medicina Legal. $3^{\text {a }}$ ed. volume II (Psicopatologia forense). Rio de Janeiro: Francisco Alves, 1938, p. 278 - nota de rodapé. 